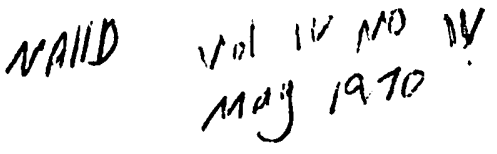

\title{
THE LANGUAGE LABORATORY AND FOREIGN LANGUAGE TDACHER TRAINING
}

\section{by Zoltan Meder}

\section{University of Wisconsin - Milwaukee}

No matter how significant its function, the FL laboratory represents but one aspect of the total FL learning process. In turn, this process, reflected too often in haphazardly accepted and applied methods, needs to grow out of a clearly and realistically defined set of objectives based on pertinent philosophical, psychological, and consequent methodological considerations.

The involvement of the FL teacher candidate in the use of the FL laboratory will be an important and critical factor in his success: It can support his teaching and enhance learning, and it can turn into a tolerated source of pain and frustration, or mere busy work both for the teacher and the student.

How can we best prepare our FL teachers to work with the FL laboratory as a well accepted, truly purposeful instrument of learning and to share decision-making with those in charge of setting forth FL educational objectives and guiding the use of the FL laboratory?

Dpir Most teacher candidates will have had a few years of FL study in high school with encouraging success experiences. These years include their first exposures to work in the FL laboratory - as recipients of the instruction. Their exposures vary greatly. Some have frequent work in S-R-C-R practice; others, only incidental drills in totally under-equipped laboratories. And some have no exposure to FL laboratory work.

The gaps in the quality of laboratory instruction, in the frequency of use, in the purposefulness of use, and in the coordination of laboratory work to the instructional materials and to the teaching method practiced in the classroom are too many to enumerate.

On the college level (except at the most dynamic universities) these FL students continue to be recipients of FL laboratory instruction, or worse, they receive advancement into intermediate level courses. At most universities and colleges, FL laboratory work is no longer required. Since numerous schools in every state still have no foreign language laboratories but do turn out students who can be placed in intermediate level courses, some clientele enter their professional FL teaching methods course and in some places begin their practice teaching experience without having had even a recipient's experience in the FL laboratory. 
This gap can be narrowed to a minimum by close cooperation be- $N \theta$. tween the Letters-Science-Arts Foreign Language Departments and the Schools of Education in the coordinate planning, the carrying out of FL teacher training, and in securing FL Laboratory experiences for the FL teacher candidates both as recipients and as teacher-in-charge of laboratory instruction.

At our university we began moving in this direction. The offer for assistance of the $L+S$ language laboratory staff has been quick and gallant. Our methods course students volunteer enthusiastically to participate in the six hours laboratory tutorial sessions conducted by the assistant directors on a $2-1$ basis.

The third exposure of teacher candidates to FL laboratory work is in the host school where they practice teach. How much the teacher candidate gains in FL laboratory experience in this setting is generally a matter of luck; it depends largely on the knowledge, concern, and orientation of the cooperating teacher. Even after NDEA Institute participation, many cooperative teachers neglect the FL Laboratory or misuse it. Some teachers have learned little more about the function of the laboratory than the plugs on the console board and that laboratory practice should follow classroom work and memorization. Others insist on introducing new drill materials in the laboratory, using these sessions chiefly for grading purposes, or are assigned halfway supervision duties during laboratory sessions with a disciplinarian watching the students in the booths.

Thus, in most places, the responsibility for preparing teacher $r$ candidates for the knowledge and effective use of the laboratory rests within the FL methods course.

Within this course in the School of Education the teacher candidate has to learn about: the history and the aims of teaching FL's; trends, issues, and innovations in his field; the necessarily applicable areas of linguistics; various teaching methods; the psychology of language learning; teaching machines, text analysis, audio-visuals and how all these incorporate different theories of learning; testing and evaluation; teaching culture and literature; making methodological choices for themselves; class management and discipline and classroom routines; school climate and interpersonal relationship; class planning, procedures, motivation; their roles as teachers and as change agents - and so forth.

Most universities and colleges offer and require one 2 or 3 credit course in methodology plus everything else that has to do with actual teaching. The need is painfully pressing for securing two methods courses wherever there is only one required now: one of theory and one of practicum. 
The FL laboratory is an instrument of learning which can support practically any present trend of instruction. It can be readily subordinate in its use to various methods born out of different considerations regarding philosophical objectives (e.g. utilitarian or intellectual values), linguistic orientation or a pedagogical view (e.g. begin with the native speaker's shorter utterances with little regard to grammatical complexity or move from the simple toward the more complex), and a psychological position (e.g. FL learning: a mechanical process of habit formation or a deep psychological and intellectual involvement).

The teacher candidate has to gain sufficient knowledge in language learning theory so he can believe in what and how he will conduct his use of the FL laboratory. Only this knowledge, his awareness of the alternatives, can equip him to make a choice.

That choice is open to him. Presently little empirical research can be named in suppont of either the pattern approach or other conversationally oriented approaches. There is no conclusive analysis in whether grammar can be best taught by induction or deduction or a combination of both. Mueller has to perceive structural signals even after intensive drill. Carroll sets forth the hypothesis that specific practice in selecting and transforming patterns leads to conversational ability more rapidly than a repetitive practice of the patterns themselves. Thus, who can decide for the teacher candidate, just to what extent he should bind himself to the memorizer drills in his teaching, how much faith he should have in the automatic response or in the more spontaneous producing of the language, to what extent he should chose to improvise his own drill practices?

The teacher candidate must become familiar with language theory and significant research, and he must be aided in developing his insights on the basis of which he can recognize his own deeper preference for the method and for the kind of FL laboratory use that suits him best - not rigidly so, but for the time being. Then he can determine his own objectives and, depending on these objectives, the method.

While in agreement that language learning is partly a process of habit formation perfectly fitting for laboratory practices as they are conducted in most of our schools, we can encourage the teacher candidate not to lose sight of the motivating power of personalized communication experiences in which the want to express one-self and to be understood by another person is fulfilled - even in the simplest question-answer verbalization. There is excitement in the want to play with foreign words for communication. Essentially, this is similar to Mowrer's idea of moving out from within the inner subjective field 
toward a gratifying experience of the self. Dunkel supports this view in proposing that only through some form of trial-and-error practice will the student have the opportunity to practice self-expression arrangements of the foreign language forms he has learned. If he is continuously in the stimulus-correct response-reward situation, he will not be able to find himself in a dynamic learning dilemma to develop that wonderful adventurous spirit which would motivate him to put what he knows to fullest use.

Pure efficiency orientation or the great game of learning? Perhaps a reasonable combination of both. The choice, however, should remain a privilege of the knowledgeable teacher candidate." It is he who will have to live with himself as a teacher. He will then want and be able to decide how to put the FL laboratory to maximum use toward his objectives.

The potential of the FL laboratory and the numerous audio-visuals in FL teaching have been hardly tapped yet.

The acquisition of perfect, native-like pronunciation on the beginning level has proved to be wishful thinking - save for some rare exceptions. The usual FL laboratory, even with a S-R-C-R-C cycle, leaves much to be desired: the student is still in no position to evaluate his pronunciation. Now truly individualized addition to FL laboratory training in pronunciation is becoming available through the SAID (Speech Auto-Instructional Device), developed at the Center for Research on Language and Language Behavior. This instrument presents tape-recorded sentences to the student for imitation. In the next step the computerized system processes the student's response and evaluates it on the basis of pitch, loudness, and speed. Then it displays immediately to the student the degree to which his utterances is unacceptable and demonstrates how he must modify his next attempt to make his pronunciation acceptable. This process of presentation-evaluation-display repeats itself until the student's presentation becomes acceptable.

The importance of visual learning in FL instruction is being stressed more and more. Impressive Spanish and French audiovisual courses have already been accepted widely. The $8-\mathrm{mm}$. cartoon cassette, popular in FL teaching in Europe, is beginning to make vital contributions to FL instruction in some of our schools, tying pictorial sequences to auditive, visual, oral, and factual memory components in learning.

Video-taped micro-lessons are already supporting the training of teaching assistants in LSA Foreign Language Department and FL teacher candidates in the Schools of Education. Foreign Language 
Media Laboratories are needed for the teacher candidates' heruiskeninvolvement and individual follow-up work in areas of his special interests that can never be "covered" for all students in a scheduledclass situation.

The FL teacher candidates need to be prepared to work and to be successful in the framework of FL education as it exists, and they need to be prepared to incorporate the technical advances of tomorrow. The FL laboratory will become an integral part of the foreign language "environment" which we hope will represent a near replica of the foreign atmosphere in which language learning and a process of acculturation would be "a happening from within." 